\title{
Incentivizing fruit and vegetable purchases among participants in the Special Supplemental Nutrition Program for Women, Infants, and Children
}

\author{
Tatiana Andreyeva* and Joerg Luedicke \\ Rudd Center for Food Policy and Obesity, Yale University, 309 Edwards Street, New Haven, CT 06520-8369, USA
}

Submitted 9 October 2013: Final revision received 5 March 2014: Accepted 7 March 2014: First published online 9 May 2014

\begin{abstract}
Objective: In 2009, the US Special Supplemental Nutrition Program for Women, Infants, and Children (WIC) began to provide participants with cash-value vouchers to purchase fruits and vegetables (\$US 10 for women and \$US 6 for children per month). The present paper assesses the potential effects of the new WIC incentives on fruit and vegetable purchases among WIC households in two New England states.

Design: A pre-post assessment of changes in fruit and vegetable purchases after the WIC revisions in generalized estimating equation models.

Setting: Scanner data on grocery purchases from a regional supermarket chain in New England, USA.

Subjects: WIC-participating households ( $n$ 2137) that regularly shopped at the chain during January-September 2009 and January-September 2010.

Results: After the WIC revisions, purchases of fresh and frozen vegetables increased in volume by $17.5 \%$ and $27 \cdot 8 \%$, respectively. The biggest improvements were observed for fresh fruit, an increase of $28.6 \%$, adding almost a kilogram of fresh fruits per household per month. WIC households spent three times more of their WIC vouchers on purchasing fresh fruits than fresh vegetables. The magnitudes of substitution effects were relatively small: between $4 \%$ (fresh fruit) and $13 \%$ (canned vegetables) of the amounts purchased in 2009 with non-WIC funds were replaced by purchases made using WIC vouchers in 2010.

Conclusions: The provision of fruit and vegetable benefits in the revised WIC food packages increased overall purchases of fruits and vegetables among WICparticipating households in New England. Efforts to encourage consumption of fruits and vegetables by people receiving federal food assistance are paying off.
\end{abstract}

Increasing consumption of fruits and vegetables is one of the main recommendations in the Dietary Guidelines for Americans ${ }^{(1)}$. Diets rich in fruits and vegetables can reduce chronic disease risk ${ }^{(2,3)}$, help with long-term weight maintenance ${ }^{(4-6)}$ and prevent deficiency in important nutrients that are often underconsumed in the USA, such as folate, potassium and dietary fibre ${ }^{(1)}$. Despite clinical and public health recommendations to consume more fruits and vegetables, the US rates of adequate fruit and vegetable consumption are very low, particularly among low-income populations $^{(7,8)}$. For example, the US government recommends that people aged 2 years and above consume at least two daily servings of fruits and at least three daily servings of vegetables, but only $32.5 \%$ of adults met this benchmark for fruits and $26 \cdot 3 \%$ for vegetables ${ }^{(7)}$. Policies to encourage consumption of fruits and vegetables have long shaped the agenda of public health nutrition, varying from changes in nutrition education and food marketing to school meal standards and price incentives for consumers and producers.

The federal food assistance programmes can play a significant role in improving public health nutrition among programme participants. One of them, the Special Supplemental Nutrition Program for Women, Infants, and Children (WIC), serves almost half of the infants born in the USA, a quarter of children aged 5 years and under, $29 \%$ of pregnant women and $26 \%$ of postpartum women, a total of almost 8.7 million people and at a cost of \$US 6.4 billion in $2013^{(9)}$. The programme serves pregnant, breastfeeding or postpartum women, infants and children aged 1-4 years who are low-income (household income below $185 \%$ of the federal poverty line) and at nutritional risk (e.g. overweight, poor diet, anaemia). Benefits to participants include a supplemental set of nutrient-dense foods in the WIC food packages (e.g. milk, juice, cereal, infant formula), nutrition education, and referrals to health care 
and social services. Federal regulations define specific WIC foods and their quantities in the WIC food packages, which vary by participant category and which participants obtain from WIC-participating retailers. Participants receive fixed cash-value vouchers (CVV) for the purchase of fruits and vegetables and quantity-based WIC food vouchers, cheques or electronic benefit cards for other foods.

WIC's targeted focus on many low-income women, infants and young children offers significant potential for early intervention to prevent obesity and poor nutrition in vulnerable populations. The WIC food packages were revised in 2007 to align them with the 2005 Dietary Guidelines for Americans and infant feeding practice guidelines of the American Academy of Pediatrics. Designed as costneutral changes and implemented in all states by October 2009, the revisions aimed to promote breast-feeding and increase consumption of fruits, vegetables and whole grains while reducing intakes of saturated fat, cholesterol and sugar ${ }^{(10)}$. The main changes included the addition of whole grain products, fruit and vegetable $\mathrm{CVV}$, reductions in milk, cheese and juice allowances, and restrictions on milk fat content.

Prior to the WIC food package revisions, WIC participants received no benefits to purchase fruits, with the exception of $100 \%$ fruit juice. Vegetables were limited to dried beans, peas and, for breast-feeding women only, canned or fresh carrots. The revised packages provide WIC-participating women and 1-4-year-old children each month with \$US 10 and \$US 6 respectively in fruit and vegetable $\mathrm{CVV}$. Eligible varieties include any fresh, frozen or canned whole or cut fruit without added sugars, fats or oils, and fresh, frozen, canned whole or cut vegetables, except white potatoes, without added sugars, fats or oils ${ }^{(11)}$. It is currently unknown how successful the new WIC fruit and vegetable benefits were in incentivizing fruit and vegetable purchases among WIC participants. Prior research has suggested that financial incentives could be an effective means of promoting healthy eating habits, including fruit and vegetable consumption ${ }^{(12)}$. The current study describes the effect of the WIC food package revisions on supermarket purchases of fruits and vegetables among WIC-participating households in New England.

\section{Methods}

\section{Scanner data}

The data were obtained from a supermarket chain with over sixty stores in two New England states. Like many other chains, the store uses a loyalty card system to attract customers with sales and promotions. At least $90-95 \%$ of all purchases at the grocery chain are made using loyalty cards. Purchases made without a loyalty card are not included in the current study. Each loyalty card is assumed to represent one household, although some families might in practice have multiple cards. Household sociodemographic characteristics, size and multiple card information were not available due to de-identified data that were provided to the study.

The data set has complete information about all purchases made by households using loyalty cards, including a list of products and amounts purchased and prices paid. Every purchase is linked to a payment method, which can include: (i) personal funds (e.g. cash, credit cards); (ii) benefits of the Supplemental Nutrition Assistance Program (SNAP, formerly known as Food Stamps); (iii) electronic benefit transfer (EBT) cash assistance (welfare type of payments); and (iv) WIC benefits via paper-based vouchers. The use of SNAP, WIC and/or cash assistance benefits indicates household participation in the respective programme at the time of the purchase. Programme participation of each household is assessed based on multiple purchases during each month of the analysis.

\section{Participants}

The sample is a subset of low-income WIC-participating families who shopped at the grocery chain stores in Connecticut or Massachusetts in January 2009-September 2010. All households using WIC benefits at any store of the chain during this time were selected. Specifically, households with at least one WIC purchase in January 2009 were flagged as WIC and were followed forward even if they no longer used WIC benefits. Newly entering WIC households were identified after January 2009 using the same approach. These households were carried forward, but their purchases prior to joining the sample were not available. About half of WIC households were also SNAP participants. No data were provided by the grocery chain for households that never participated in WIC.

The current study used data for households that participated in WIC both before and after implementation of the WIC revisions in October 2009. Households were selected if they used WIC benefits each quarter during JanuarySeptember 2009 (pre-revision period) and each quarter in January-September 2010 (post-revision period). A 3-month transition period after October 2009 was excluded to avoid data noise as the pre-revision WIC cheques were accepted for redemption up to three months after the implementation date. The final sample included 2137 WIC households providing 36051 observation-months. The study was exempt from institutional review board review due to the de-identified nature of the data.

\section{Product identification and categorization}

The grocery chain provided a description of all products sold at its stores for 392119 Universal Product Codes and, for items sold by weight, Price-Look Up codes. We included 3229 vegetable and 1733 fruit Universal Product Codes/Price-Look Up codes. Using data from the product description and the ingredient lists in the Gladson Nutrition Database ${ }^{(13)}$, fruits and vegetables were categorized into Fresh, Canned, Frozen and Dried varieties (100\% fruit 
and vegetable juice was assessed elsewhere $\left.{ }^{(14)}\right)$. Vegetables were also classified into five vegetable subgroups based on the DGA 2010: Starchy, Dark-Green, Red/Orange, Other and Beans/Peas. We also included vegetables with added fats, sugars and oils if a vegetable was the first ingredient. For example, tomato sauces with tomatoes as the primary ingredient were included as canned vegetables, yet sauces like barbeque and chilli were excluded as they provided a minimal contribution of vegetable servings. White potatoes were not included in the current study as they were not eligible for purchases with WIC vouchers. All analyses were completed for any fruits and vegetables (except white potatoes) and WIC-eligible fruits and vegetables, with qualitatively similar results.

Fruits and vegetables were coded for container size, weight and cup-equivalent servings of the consumable portion of a given item. The consumable weight of the product was calculated by removing the weight of the inedible share based on the US Department of Agriculture's per cent refuse for fresh fruits and vegetables ${ }^{(15)}$ and deriving the per cent cooking yield of the products with data from multiple sources ${ }^{(16,17)}$. Consumable weight was further converted to MyPyramid cup equivalents ${ }^{(18)}$. Details on fruit and vegetable classification are available from the authors upon request.

\section{Outcome variables}

The main outcome variables were total amounts of fruits and vegetables purchased by a WIC household in a given month, assessed in ounces and converted to grams, cup-equivalent servings and dollar expenditure. Fruit and vegetable purchases were distinguished by payment type, including purchases made with WIC benefits or CVV, non-WIC funds (e.g. cash, SNAP benefits) and all payment methods combined. Each household's purchases were aggregated at the monthly level. The presentation of marginal averages was based on distinguishing between 'all purchases' and 'purchases with WIC benefits', the difference between the two would correspond to non-WIC purchases of fruits and vegetables. Since WIC payments in the pre-revision period were zero for fruits and almost zero for vegetables, fitting (non-linear) regression models was completed for 'all purchases' and 'purchases with non-WIC funds'.

\section{Predictor variables}

The main predictor was a binary variable indicating preand post-implementation periods of the WIC food package revisions. Household-level controls included indicators for monthly household SNAP participation and receipt of cash assistance, a continuous variable of household monthly expenditure on groceries purchased at the chain, number of transactions per month and the state of purchase. A set of store-level covariates, listed in Table 1, was included to capture differences in the socio-economic composition of the store areas, which may reflect neighbourhood differences in prices, product selection and marketing and serve as proxies for unobserved household sociodemographics. Each store location was linked to a census tract with data from the 2006-2010 American Community Survey ${ }^{(19)}$. For households shopping in multiple stores, the average of census-tract measures was calculated.

As fruits and vegetables are the only products in the WIC food packages where prices matter given the fixed amount of $\mathrm{CVV}$, average monthly net sale prices for fruit/ vegetable categories were used to account for changes in prices over time. Net sale prices reflected prices paid by consumers after taking into account discounts and promotions available for specific products. Net sale prices were calculated as monthly averages across stores within each state.

\section{Model}

As all outcome variables had a natural bound at zero and were positively skewed, regression modelling was based on generalized linear models from the Poisson family with a logarithmic link function ${ }^{(20)}$. To account for repeated observations within households, generalized estimating equations were used with exchangeable working correlation and robust standard errors ${ }^{(21)}$. Adjusted mean differences between the two periods were estimated using the following generic model:

$$
\begin{aligned}
E\left[Y_{i t} \mid X_{i}, X_{i t}\right]= & \exp \left(\beta_{0}+\beta_{1} \times \text { PERIOD }_{i t}+\beta_{2} \times S_{N A P_{i t}}\right. \\
& +\beta_{3} \times \text { EBT }_{i t}+\beta_{4} \times \text { TOTEXP }_{i t}+\beta_{5} \times N T R A N S_{i t} \\
& +\beta_{6} \times \text { PRICE }_{t}+\beta_{7} \times \text { STATE }_{i}+\beta_{8} \times T_{i t} \\
& \left.+\beta_{9} \times S_{i t}\right)
\end{aligned}
$$

where $P E R I O D_{i t}$ indicates the time period ( 0 for pre- and 1 for post-implementation), $S N A P_{i t}$ indicates a household $i$ that used SNAP benefits at time $t, E B T_{i t}$ is receipt of cash assistance, TOTEXP $P_{i t}$ is total grocery expenditure at the chain, $N T R A N S_{i t}$ is the number of transactions, PRICE are average prices within respective food and vegetable categories, and $S T A T E_{i}$ is an indicator for state. $T_{i t}$ denotes a set of eight binary variables indicating the month of purchase and $S_{i t}$ is a vector of store-area sociodemographic covariates. Note that price information was not included in the expenditure models since price-adjusted expenditure would not reflect differences in total expenditure amounts. Table 1 reports descriptive statistics on variables used in the analysis.

\section{Results}

Average household total monthly expenditures on all groceries were \$US 235 in 2009 and \$US 219 in 2010. Fruit spending accounted for about $4.6 \%$ of household grocery expenditure in 2009 and $6 \cdot 2 \%$ in 2010, while the share of vegetables increased correspondingly from $5.4 \%$ to 
Table 1 Sample description: low-income WIC-participating families who shopped at stores from a regional supermarket chain in Connecticut or Massachusetts, USA, in January 2009-September 2010

\begin{tabular}{|c|c|c|c|c|}
\hline & \multicolumn{2}{|c|}{$\begin{array}{l}\text { Pre-implementation period } \\
\text { January-September } 2009\end{array}$} & \multicolumn{2}{|c|}{$\begin{array}{l}\text { Post-implementation period } \\
\text { January-September } 2010\end{array}$} \\
\hline & Mean & SD & Mean & SD \\
\hline \multicolumn{5}{|l|}{ Household-level covariates } \\
\hline SNAP participation (\%) & \multirow{2}{*}{\multicolumn{2}{|c|}{45}} & \multicolumn{2}{|c|}{52} \\
\hline Receipt of cash assistance (\%) & \multirow{2}{*}{\multicolumn{2}{|c|}{$\begin{array}{c}5 \\
23\end{array}$}} & \multicolumn{2}{|c|}{5} \\
\hline State of purchase (Connecticut) (\%) & & & \multicolumn{2}{|c|}{24} \\
\hline Total monthly grocery expenditure (\$US) & 235 & 190 & 219 & 183 \\
\hline Total monthly fruit expenditure (\$US) & $10 \cdot 79$ & $15 \cdot 69$ & 13.48 & $16 \cdot 31$ \\
\hline Total monthly vegetables expenditure (\$US) & $12 \cdot 62$ & 16.43 & $13 \cdot 72$ & $16 \cdot 68$ \\
\hline \multicolumn{5}{|l|}{ Net sale prices (\$US $/ 100 \mathrm{~g})$} \\
\hline Fresh vegetables & 0.497 & 0.043 & 0.534 & 0.044 \\
\hline Canned vegetables & 0.357 & 0.032 & 0.350 & 0.046 \\
\hline Frozen vegetables & 0.367 & 0.028 & 0.371 & 0.021 \\
\hline Fresh fruits & 0.417 & 0.032 & 0.452 & 0.039 \\
\hline Canned fruits & 0.325 & 0.021 & 0.336 & 0.021 \\
\hline Total number of transactions per period & 105 & 60 & 107 & 63 \\
\hline \multicolumn{5}{|l|}{ Store area-level sociodemographic covariates } \\
\hline Household income (in \$US 10000 ) & $5 \cdot 6$ & 1.6 & $5 \cdot 6$ & 1.6 \\
\hline High-school graduates (\%) & 33.6 & $7 \cdot 1$ & 33.6 & $7 \cdot 1$ \\
\hline College graduates $(\%)$ & $15 \cdot 9$ & $5 \cdot 8$ & $15 \cdot 9$ & $5 \cdot 8$ \\
\hline Non-English use at home (\%) & $15 \cdot 9$ & 12 & 16 & 12 \\
\hline Unemployed (\%) & $8 \cdot 1$ & $2 \cdot 8$ & 8.1 & $2 \cdot 8$ \\
\hline SNAP participants (\%) & $11 \cdot 1$ & 8.4 & $11 \cdot 2$ & 8.4 \\
\hline Households in poverty (\%) & 8.5 & $6 \cdot 4$ & 8.6 & $6 \cdot 4$ \\
\hline Non-Hispanic White (\%) & 83.5 & $13 \cdot 3$ & 83.5 & $13 \cdot 2$ \\
\hline Non-Hispanic Black (\%) & 3.8 & $5 \cdot 3$ & 3.7 & $5 \cdot 1$ \\
\hline$n$ (observations) & \multirow{2}{*}{\multicolumn{2}{|c|}{$\begin{array}{c}17740 \\
2137\end{array}$}} & \multirow{2}{*}{\multicolumn{2}{|c|}{$\begin{array}{c}18311 \\
2137\end{array}$}} \\
\hline$n$ (households) & & & & \\
\hline
\end{tabular}

WIC, Special Supplemental Nutrition Program for Women, Infants, and Children; SNAP, Supplemental Nutrition Assistance Program (formerly known as Food Stamps).

Note: Household sociodemographic covariates are not available in the data.

6.3\% (Table 1). In both 2009 and 2010, the most purchased vegetables were fresh and canned varieties, where canned included items such as ketchup and pickles. Fresh vegetables accounted for $60 \%$ of total vegetable cup-equivalent servings and vegetable expenditure in MA and 56\% in CT in 2009 (Table 2). Based on cup-equivalent servings, the most popular vegetables among WIC households in 2009 were other vegetables (e.g. celery, mushrooms, olives), which accounted for about $40 \%$ of all purchased vegetables. Red and orange vegetables (e.g. carrots, tomatoes) were the second most popular (29\%), followed by dark-green (13\%), starchy vegetables (11\%), and beans and peas (7\%). This was similar for expenditure and changed little in 2010. As WIC provided a very limited set of vegetables before the WIC revisions, vegetable purchases using WIC benefits were minimal in 2009.

This changed significantly in 2010, with vegetables purchased using WIC benefits accounting for $19 \%$ of all vegetable purchases among WIC households in MA and $10 \%$ in CT (respectively, $838 \mathrm{~g}$ and $464 \mathrm{~g}$ per household per month). There were important substitution effects: instead of adding all of the new WIC benefits to the prerevision vegetable purchases, WIC households used them to pay for some of the vegetables previously purchased with non-WIC payments (i.e. cash, SNAP benefits). NonWIC purchases of vegetables declined by $492 \mathrm{~g}$ in MA and $433 \mathrm{~g}$ in CT (about 3 cup-equivalent servings and \$US 0.4-0.6 per month).

Most fruit purchases were for fresh fruits (of cupequivalent servings, $89 \%$ in 2009 and $92 \%$ in 2010), with only modest amounts of canned fruits (8\% in 2009 and $6 \%$ in 2010) and minimal purchases of frozen and dried fruit (2-3\%; Table 3). Average spending on fruits by WIC households was similar to their vegetable expenditure, about \$US 11-14 per household per month or $5 \%$ of total monthly expenditure at the grocery chain. All fruit purchases prior to the WIC revisions were made using non-WIC funds.

In 2010, WIC benefits accounted for about a quarter of all fruit purchases among WIC households. Specifically, WIC-paid purchases of fruit (almost all fresh fruit) per household per month increased from zero to $976 \mathrm{~g}$ in MA and $1039 \mathrm{~g}$ in CT, which is about 5 cup-equivalent servings and $\$$ US $3 \cdot 1-3 \cdot 3$. However, total fruit purchases increased by 566-662 g per month (3.5 cup-equivalents or \$US $2 \cdot 6-2 \cdot 7$ ), indicating the same substitution effects observed with vegetable purchases. A change in the method of payment from non-WIC funds in 2009 to WIC benefits in 2010 accounted for about $10 \%$ of fruit purchases by weight and $5 \%$ of spending.

Table 4 shows estimation results for fresh, canned and frozen vegetable purchases and fresh and canned fruit purchases in grams and dollar expenditure. Due to small 
Table 2 Vegetable purchases before (2009) and after (2010) implementation of the WIC food package revisions (unadjusted analyses) among low-income WIC-participating families who shopped at stores from a regional supermarket chain in Connecticut or Massachusetts, USA, in January 2009-September 2010

\begin{tabular}{|c|c|c|c|c|c|c|}
\hline & \multicolumn{2}{|c|}{ Grams } & \multicolumn{2}{|c|}{ Cup-equivalent servings } & \multicolumn{2}{|c|}{ Expenditures (\$US) } \\
\hline & MA & CT & MA & $\mathrm{CT}$ & MA & $\mathrm{CT}$ \\
\hline & \multicolumn{6}{|c|}{ All purchases } \\
\hline \multicolumn{7}{|l|}{2009} \\
\hline Fresh vegetables & 2164.9 & $2258 \cdot 3$ & 13.7 & 14.6 & $7 \cdot 1$ & $8 \cdot 1$ \\
\hline Canned vegetables & $1550 \cdot 8$ & 1839.5 & 6.5 & $7 \cdot 7$ & 3.8 & 4.6 \\
\hline Frozen vegetables & $305 \cdot 6$ & $461 \cdot 3$ & $1 \cdot 8$ & $2 \cdot 7$ & 0.9 & $1 \cdot 3$ \\
\hline Dried vegetables & $48 \cdot 1$ & $62 \cdot 3$ & 0.6 & 0.9 & 0.2 & 0.2 \\
\hline Total & 4069.5 & 4621.4 & $22 \cdot 6$ & $25 \cdot 9$ & 11.9 & $14 \cdot 2$ \\
\hline \multicolumn{7}{|l|}{2010} \\
\hline Fresh vegetables & $2278 \cdot 2$ & 2391.4 & $13 \cdot 8$ & 14.8 & $7 \cdot 8$ & $9 \cdot 2$ \\
\hline Canned vegetables & $1610 \cdot 3$ & $1635 \cdot 7$ & $6 \cdot 7$ & $7 \cdot 0$ & $4 \cdot 0$ & $4 \cdot 3$ \\
\hline Frozen vegetables & $413 \cdot 2$ & $478 \cdot 3$ & $2 \cdot 4$ & $2 \cdot 8$ & $1 \cdot 2$ & 1.3 \\
\hline Dried vegetables & $31 \cdot 1$ & $62 \cdot 3$ & 0.4 & 0.9 & 0.1 & 0.2 \\
\hline \multirow[t]{2}{*}{ Total } & $4332 \cdot 7$ & 4567.6 & $23 \cdot 3$ & $25 \cdot 5$ & $13 \cdot 2$ & 14.9 \\
\hline & \multicolumn{6}{|c|}{ Purchases with WIC benefits } \\
\hline \multicolumn{7}{|c|}{ 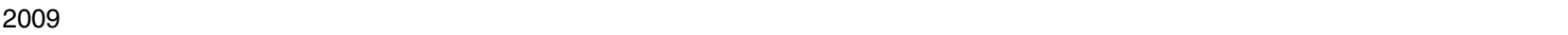 } \\
\hline Fresh vegetables & $28 \cdot 3$ & $19 \cdot 8$ & 0.2 & 0.1 & 0.1 & 0 \\
\hline Canned vegetables & $14 \cdot 2$ & $16 \cdot 9$ & 0.1 & 0.1 & 0.1 & 0.1 \\
\hline Frozen vegetables & 0 & 0 & 0 & 0 & 0 & 0 \\
\hline Dried vegetables & $39 \cdot 6$ & $48 \cdot 1$ & 0.5 & 0.7 & 0.1 & 0.2 \\
\hline Total & $82 \cdot 1$ & 84.9 & 0.8 & 0.9 & 0.2 & 0.3 \\
\hline \multicolumn{7}{|l|}{2010} \\
\hline Fresh vegetables & $348 \cdot 1$ & 308.5 & $2 \cdot 0$ & 1.9 & 0.9 & 1.0 \\
\hline Canned vegetables & $322 \cdot 6$ & $28 \cdot 3$ & $1 \cdot 3$ & 0.2 & 0.7 & 0.1 \\
\hline Frozen vegetables & 141.5 & $73 \cdot 6$ & 0.8 & 0.4 & 0.4 & 0.2 \\
\hline Dried vegetables & 25.5 & 53.8 & 0.3 & 0.7 & 0.1 & 0.1 \\
\hline Total & 837.7 & $464 \cdot 1$ & $4 \cdot 4$ & $3 \cdot 2$ & $2 \cdot 1$ & 1.4 \\
\hline$n$ & 27585 & 8466 & 27585 & 8466 & 27585 & 8466 \\
\hline
\end{tabular}

WIC, Special Supplemental Nutrition Program for Women, Infants, and Children.

Note: Before implementation of the WIC food package revisions (2009), the WIC food packages included only dried beans/peas and fresh/canned carrots. No other vegetables were allowed. White potatoes are not included.

purchases of dried fruit and vegetables and frozen fruits, these were not included in the estimation. Results show the change in fruit and vegetable purchases following implementation of the WIC food package revisions, adjusting for seasonal variation, fruit/vegetable prices and other control variables. In 2010, the monthly amount of fresh vegetables purchased was $2.52 \mathrm{~kg}$, an increase of $17.5 \%(P<0.001)$ from 2009. The increase in expenditure on vegetables was similar in magnitude, $14.7 \%(P<0 \cdot 001)$ for fresh vegetables and $30.9 \%(P<0.001)$ for frozen vegetables, which is only additional \$US 1.14 per month for fresh vegetables. Results for vegetable purchases using non-WIC funds confirm substitution effects seen in the descriptive data.

The estimated differences for fresh vegetables would be smaller (e.g. $\exp (b)=1 \cdot 110, P<0.001$ for any payment) if changes in net sale vegetable prices were not included in the estimation. This is due to a slight increase in average prices for fresh vegetables between 2009 and 2010 (3 cents/g in MA and CT). On the other hand, prices for canned vegetables decreased during the same period (about 0.5 cents/g in CT), so that the price-unadjusted effects of the time variable were $\operatorname{larger}(\exp (b)=1.037$, $P<0 \cdot 05)$. No changes in prices and estimation results were observed for frozen vegetables.
The results for fruits were similar to the vegetable findings, suggesting a significant increase of $28.6 \%(P<0.001)$ in purchased grams of fresh fruit and $30.3 \%(P<0.001)$ higher spending. An average WIC household purchased additional $906 \mathrm{~g}$ and spent \$US 3.12 more on fresh fruits per month; more than double the increases seen for fresh vegetables. These improvements in total (WIC and non-WIC) fruit purchases occurred while WIC households reduced the amounts of fresh and canned fruit purchases made using non-WIC funds, by $4.4 \%(P<0.05)$ and $12.1 \%(P<0.001)$ respectively. A small increase in average prices for fresh fruits between 2009 and 2010 led to slightly larger coefficients (e.g. coefficient for the difference in fresh fruit purchases excluding prices, any payment: $\exp (b)=1 \cdot 252$, $P<0.001)$. Prices for canned fruits did not change over the two time periods. The online supplementary material presents supplemental data on the variation in fruit and vegetable purchases and changes in their prices.

\section{Discussion}

Increasing fruit and vegetable consumption in low-income women and young children was one of the key goals in revising the WIC food packages ${ }^{(10)}$. For WIC-participating 
Table 3 Fruit purchases before (2009) and after (2010) implementation of the WIC food package revisions (unadjusted analyses) among low-income WIC-participating families who shopped at stores from a regional supermarket chain in Connecticut or Massachusetts, USA, in January 2009-September 2010

\begin{tabular}{|c|c|c|c|c|c|c|}
\hline & \multicolumn{2}{|c|}{ Grams } & \multicolumn{2}{|c|}{ Cup-equivalent servings } & \multicolumn{2}{|c|}{ Expenditures (\$US) } \\
\hline & MA & CT & MA & CT & MA & $\mathrm{CT}$ \\
\hline & \multicolumn{6}{|c|}{ All purchases } \\
\hline 2009 & & & & & & \\
\hline Fresh fruit & $3036 \cdot 6$ & $3234 \cdot 7$ & $15 \cdot 0$ & $16 \cdot 0$ & $9 \cdot 5$ & $10 \cdot 0$ \\
\hline Canned fruit & 311.3 & 376.4 & $1 \cdot 3$ & 1.6 & 0.8 & 0.9 \\
\hline Frozen fruit & $19 \cdot 8$ & $19 \cdot 8$ & $0 \cdot 1$ & $0 \cdot 1$ & $0 \cdot 1$ & 0.1 \\
\hline Dried fruit & 25.5 & $28 \cdot 3$ & 0.3 & 0.3 & 0.2 & 0.2 \\
\hline Total & $3393 \cdot 2$ & $3659 \cdot 2$ & $16 \cdot 7$ & $18 \cdot 0$ & $10 \cdot 6$ & $11 \cdot 3$ \\
\hline \multicolumn{7}{|l|}{2010} \\
\hline Fresh fruit & 3684.7 & $3882 \cdot 8$ & $18 \cdot 4$ & 19.5 & $12 \cdot 0$ & $12 \cdot 7$ \\
\hline Canned fruit & $314 \cdot 1$ & $302 \cdot 8$ & $1 \cdot 3$ & 1.3 & 0.9 & 0.9 \\
\hline Frozen fruit & $28 \cdot 3$ & $19 \cdot 8$ & $0 \cdot 1$ & 0.1 & 0.2 & 0.1 \\
\hline Dried fruit & $28 \cdot 3$ & $19 \cdot 8$ & 0.3 & 0.2 & 0.2 & 0.2 \\
\hline Total & $4055 \cdot 4$ & $4225 \cdot 2$ & $20 \cdot 1$ & $21 \cdot 1$ & $13 \cdot 4$ & $13 \cdot 9$ \\
\hline & \multicolumn{6}{|c|}{ Purchases with WIC benefits } \\
\hline \multicolumn{7}{|c|}{ 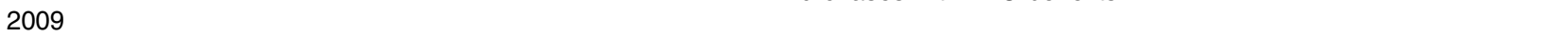 } \\
\hline Fresh fruit & 0 & 0 & 0 & 0 & 0 & 0 \\
\hline Canned fruit & 0 & 0 & 0 & 0 & 0 & 0 \\
\hline Frozen fruit & 0 & 0 & 0 & 0 & 0 & 0 \\
\hline Dried fruit & 0 & 0 & 0 & 0 & 0 & 0 \\
\hline \multicolumn{7}{|l|}{2010} \\
\hline Fresh fruit & $976 \cdot 4$ & $1038 \cdot 6$ & 4.9 & $5 \cdot 4$ & $3 \cdot 1$ & 3.3 \\
\hline Canned fruit & 42.4 & 5.7 & 0.2 & 0 & 0.1 & 0 \\
\hline Frozen fruit & 8.5 & $2 \cdot 8$ & 0 & 0 & 0.1 & 0 \\
\hline Dried fruit & 0 & 0 & 0 & 0 & 0 & 0 \\
\hline Total & $1027 \cdot 3$ & $1047 \cdot 1$ & $5 \cdot 1$ & 5.4 & $3 \cdot 3$ & $3 \cdot 3$ \\
\hline$n$ & 27585 & 8466 & 27585 & 8466 & 27585 & 8466 \\
\hline
\end{tabular}

WIC, Special Supplemental Nutrition Program for Women, Infants, and Children.

Note: Fruit was not part of the WIC food packages and could not be purchased with WIC benefits before implementation of the WIC revisions (2009). White potatoes are not included.

households in New England, the current study found significant improvements in fruit and vegetable purchases, especially for fresh fruit and vegetables, which likely increased consumption of these wholesome foods in the WIC population. The observed advances were most substantial for fresh fruits (additional monthly purchases of $906 \mathrm{~g}, 3.5$ cup-equivalent servings and \$US 3.12 per household), with WIC households spending more of their WIC fruit and vegetable CVV on fresh fruits. Increases in purchases of fresh vegetables were about $40 \%$ of the improvements seen for fresh fruits.

Another important finding of the study was to demonstrate substitution effects in the use of WIC benefits and non-WIC funds in fruit and vegetable purchases among WIC households. With the exception of fresh vegetables, the amounts of fruits and vegetables purchased with non-WIC funds declined after implementation of the WIC revisions. WIC households used their new WIC fruit and vegetable benefits to pay for some of these purchases. This substitution in the method of payment was fairly small (between $4 \%$ and $13 \%$ ), which is good news, as there was concern that WIC benefits would be used entirely to simply replace purchases made using non-WIC funds prior to the introduction of WIC fruit and vegetable CVV. As the study focused only on fruits and vegetables, it cannot describe where the 'saved' grocery funds were redirected to and how that affected overall grocery purchases and diet of WIC households. Future research should examine the effect of the WIC revisions on the composition of all food purchases and diet quality among WIC participants.

The study highlights an important disconnect between national recommendations and household choices regarding fruits and vegetables. The US Department of Agriculture recommends that families spend between \$US 45 and \$US 90 per week on at-home consumption of fresh fruits and vegetables $^{(22,23)}$. At the same time, an average household's spending on fresh fruits and vegetables for consumption at home was \$US 9.0 per week, varying from \$US 5.4 for low-income ( 1.7 persons per household) to \$US 15.0 for high-income families (3.2 persons per household) ${ }^{(24)}$. In our data, monthly spending on fresh fruits and vegetables among WIC households at one grocery chain was \$US 18.1 in 2009 and \$US 22.4 in 2010. This is similar to the national data for low-income households, but considerably lower than the recommended fruit and vegetable spending, even if the observed purchases represented only a portion of total household purchases.

There is also an important difference in how much WIC contributes to incentivizing fruit and vegetable purchases $v$. other WIC foods. For example, WIC-participating children receive 3.78 litres of $100 \%$ juice per month ${ }^{(11)}$, which is in excess of dietary recommendations for juice consumption in 
Table 4 Adjusted differences in fruit and vegetable purchases before and after implementation of the WIC food package revisions among low-income WIC-participating families who shopped at stores from a regional supermarket chain in Connecticut or Massachusetts, USA, in January 2009-September 2010

\begin{tabular}{|c|c|c|c|c|c|c|c|c|}
\hline & \multicolumn{4}{|c|}{ Vegetables } & \multicolumn{4}{|c|}{ Fruits } \\
\hline & \multirow[b]{2}{*}{$\exp (b)$} & \multirow[b]{2}{*}{$95 \% \mathrm{Cl}$} & \multicolumn{2}{|c|}{ Marginal prediction (g) } & \multirow[b]{2}{*}{$\exp (b)$} & \multirow[b]{2}{*}{$95 \% \mathrm{Cl}$} & \multicolumn{2}{|c|}{ Marginal prediction (g) } \\
\hline & & & 2009 & 2010 & & & 2009 & 2010 \\
\hline \multicolumn{9}{|c|}{ Grams purchased } \\
\hline \multicolumn{9}{|c|}{ All purchases } \\
\hline Fresh & $1 \cdot 175^{\star \star \star}$ & $1.127,1.225$ & 2151 & 2519 & $1 \cdot 286^{\star \star \star}$ & $1.238,1.335$ & 3198 & 4104 \\
\hline Canned & 1.016 & $0.980,1.052$ & 1641 & 1670 & 0.984 & $0.915,1.057$ & 311 & 311 \\
\hline Frozen & $1.278^{\star \star \star}$ & $1.198,1.363$ & 340 & 453 & n.e. & & & \\
\hline All $\dagger$ & $1.087^{\star \star \star}$ & $1.050,1.128$ & 4302 & 4670 & $1.259^{* \star *}$ & $1.215,1.306$ & 3594 & 4528 \\
\hline \multicolumn{9}{|c|}{ Purchases with non-WIC funds } \\
\hline Fresh & 1.010 & $0.969,1.054$ & 2123 & 2151 & $0.956^{*}$ & $0.920,0.993$ & 3198 & 3056 \\
\hline Canned & $0.872^{\star \star \star}$ & $0.842,0.904$ & 1613 & 1415 & $0.879^{\star \star \star}$ & $0.817,0.946$ & 311 & 283 \\
\hline Frozen & $0.904^{\star \star}$ & $0.847,0.965$ & 340 & 311 & n.e. & & & \\
\hline All $\dagger$ & $0.923^{\star \star \star}$ & $0.892,0.956$ & 4302 & 3962 & $0.950^{\star *}$ & $0.916,0.986$ & 3622 & 3424 \\
\hline \multicolumn{9}{|c|}{ Expenditures (\$US) } \\
\hline \multicolumn{9}{|c|}{ All purchases } \\
\hline Fresh & $1 \cdot 147^{\star \star \star}$ & $1.116,1.179$ & $7 \cdot 80$ & 8.94 & $1 \cdot 303^{\star \star \star}$ & $1.268,1.339$ & $10 \cdot 31$ & 13.43 \\
\hline Canned & $1.074^{\star \star \star}$ & $1.041,1.108$ & 4.03 & $4 \cdot 32$ & $1.095^{\star}$ & $1.022,1.174$ & 0.84 & 0.92 \\
\hline Frozen & $1 \cdot 309^{\star \star *}$ & $1.232,1.391$ & 1.02 & 1.33 & n.e. & & & \\
\hline All $†$ & $1 \cdot 107^{\star \star \star}$ & $1.075,1.141$ & 13.53 & 14.98 & $1.233^{\star \star *}$ & $1.193,1.274$ & 11.89 & 14.65 \\
\hline \multicolumn{9}{|c|}{ Purchases with non-WIC funds } \\
\hline Fresh & 1.025 & $0.998,1.054$ & $7 \cdot 76$ & 7.95 & 0.980 & $0.953,1.007$ & $10 \cdot 34$ & $10 \cdot 13$ \\
\hline Canned & $0.944^{\star \star \star}$ & $0.915,0.974$ & 3.99 & 3.76 & 0.981 & $0.915,1.052$ & 0.84 & 0.83 \\
\hline Frozen & 0.976 & $0.916,1.038$ & 1.02 & 1.00 & n.e. & & & \\
\hline All $\dagger$ & 0.974 & $0.945,1.003$ & 13.49 & $13 \cdot 14$ & $0.945^{\star *}$ & $0.914,0.976$ & 11.93 & 11.27 \\
\hline
\end{tabular}

WIC, Special Supplemental Nutrition Program for Women, Infants, and Children; n.e., not estimated.

Note: Full model results are available from the authors upon request.

Presented are exponentiated coefficients $(\exp (b))$, $95 \%$ confidence intervals, and marginal predictions for the binary variable indicating the time periods before (January-September 2009) and after (January-September 2010) the WIC food package revisions from separate generalized estimating equation regression models with a logarithmic link function (Poisson family) and robust standard errors; all models included control variables as shown in equation (1), except prices were not included in the expenditure models.

Significance level: ${ }^{\star} P<0.05,{ }^{\star \star} P<0.01,{ }^{\star \star \star} P<0.001$.

†Fresh, canned, frozen and dried fruit; fresh, canned, frozen and dried vegetables, vegetable juice.

young children (about $118 \mathrm{ml} / \mathrm{d})^{(25,26)}$. Similarly, WIC milk provisions cover virtually all dairy needs of young children (15.1 litres/month) ${ }^{(11)}$. At the same time, fruit and vegetable benefits for WIC-participating women and children are only \$US 10 and \$US 6 per month, which falls considerably short of the recommended fruit and vegetable spending. While the addition of fruit and vegetable CVV into the WIC food packages was an important step in promoting fruit and vegetable consumption in low-income populations, more work is necessary in closing the gap between the recommended and actual levels of fruit and vegetable intake.

If the observed purchase improvements reflect changes in fruit and vegetable consumption among WIC participants nationwide, the effects on public health could be significant. The increase in fruit and vegetable consumption is associated with a range of health outcome improvements ${ }^{(1)}$. Similar results on the effectiveness of food policy changes are available elsewhere. A randomized controlled trial, the Healthy Incentives Pilot (HIP), evaluated the effects of providing SNAP participants with a $30 \%$ subsidy on purchases of targeted fruits and vegetables (defined in a similar way as WIC-eligible fruits and vegetables). Adult SNAP participants receiving a subsidy increased consumption of targeted fruits and vegetables by 0.22 cup-equivalents per day, which is a $25 \%$ difference in consumption over a control group of SNAP participants not receiving a subsidy ${ }^{(27)}$. At the same time, the WIC food package revisions, which significantly limited juice benefits, were shown to reduce WIC participants' purchases of $100 \%$ juice by $24 \%^{(14)}$. In 2004, New York City public schools removed whole milk and switched from low-fat to fat-free chocolate milk, which led to serving 24.9 fewer megajoules (5960 fewer calories) and 619 fewer grams of dairy fat to students drinking milk in $2009^{(28)}$.

The present study has a number of unique strengths, including the use of scanner data on grocery purchases in the pre-post implementation period for over 2000 WIC families. Data on the method of payment allowed assessment of the use of WIC benefits and other funds to pay for fruits and vegetables. The study was also subject to limitations. Data were from two New England states that may differ from other states. Lack of household sociodemographic characteristics was another limitation, yet all households were WIC participants and therefore lowincome. Lack of a control group for WIC participants was another study limitation. It is also unknown how purchases made without using loyalty cards differed from purchases of loyalty card users as well as household 
purchases made with more than one loyalty card. Finally, the study assessed fruit and vegetable purchase behaviours at a single grocery chain, which does not include household purchases of fruits and vegetables across all food stores and may not represent the overall diet of WIC participants.

Future research should evaluate the effects of the WIC food package revisions on diet quality, body weight and health outcomes among WIC participants. Eating habits and body weight status in early childhood are critical for future development of the child, including risk for obesity ${ }^{(29)}$ and related health conditions. The improvements in diet, which the WIC food package revisions are likely to initiate, might have significant long-term effects on health-care costs and productivity for both private and public payers. Given the cost-neutral design of the WIC food package revisions, the current and future benefits to WIC participants could produce an impressive return on investment for taxpayers. The federal government is advised to extend the lessons learned' from the WIC revisions to updating other federal food assistance programmes, particularly SNAP.

\section{Conclusion}

The provision of fruit and vegetable benefits in the revised WIC food packages increased overall purchases of fruits and vegetables among WIC-participating households in New England. Importantly, the magnitudes of substitution effects were relatively small: between $4 \%$ (fresh fruit) and $13 \%$ (canned vegetables) of the amounts purchased in 2009 using non-WIC funds were replaced with purchases made using WIC benefits. Additional efforts to encourage fruit and vegetable consumption are necessary as fruit and vegetable purchases remain relatively low.

\section{Acknowledgements}

Acknowledgements: The authors thank Amanda Tripp, Victoria Zigmont and Ann Middleton for excellent research assistance. Special thanks are extended to the confidential grocery store chain for sharing its data. Financial support: The study was funded by a grant (\# 59-5000-8-0127) from the Economic Research Service (ERS) at the US Department of Agriculture (USDA). The views expressed in this article are those of the authors and do not necessarily represent the official views of the ERS or USDA. The ERS and USDA had no role in the design, analysis or writing of this article. Conflict of interest: None. Authorship: T.A. conceptualized and designed the study, drafted and revised the initial manuscript, and approved the final manuscript as submitted. J.L. contributed to the study design, carried out the data analyses, contributed to drafting the manuscript and interpretation of results, and approved the final manuscript as submitted. Ethics of human subject participation: Ethical approval was not required.

\section{Supplementary material}

To view supplementary material for this article, please visit http://dx.doi.org/10.1017/S1368980014000512

\section{References}

1. US Department of Agriculture \& US Department of Health and Human Services (2010) Dietary Guidelines for Americans, 2010, 7th ed. Washington, DC: U.S. Government Printing Office; available at http://health.gov/dietaryguidelines/ dga2010/DietaryGuidelines2010.pdf

2. Hung HC, Joshipura KJ, Jiang R et al. (2004) Fruit and vegetable intake and risk of major chronic disease. $J$ Natl Cancer Inst 96, 1577-1584.

3. He FJ, Nowson CA \& MacGregor GA (2006) Fruit and vegetable consumption and stroke: meta-analysis of cohort studies. Lancet 367, 320-326.

4. He K, Hu FB, Colditz GA et al. (2004) Changes in intake of fruits and vegetables in relation to risk of obesity and weight gain among middle-aged women. Int J Obes Relat Metab Disord 28, 1569-1574.

5. Rolls BJ, Ello-Martin JA \& Tohill BC (2004) What can intervention studies tell us about the relationship between fruit and vegetable consumption and weight management? Nutr Rev 62, 1-17.

6. Buijsse B, Feskens EJ, Schulze MB et al. (2009) Fruit and vegetable intakes and subsequent changes in body weight in European populations: results from the project on Diet, Obesity, and Genes (DiOGenes). Am J Clin Nutr 90, 202-209.

7. Centers for Disease Control and Prevention (2010) Statespecific trends in fruit and vegetable consumption among adults - United States, 2000-2009. Morb Mortal Wkly Rep 59, 1125-1130.

8. Centers for Disease Control and Prevention (2007) Fruit and vegetable consumption among adults - United States, 2005. Morb Mortal Wkly Rep 56, 213-217.

9. Oliveira V \& Frazão E (2009) The WIC Program: Background, Trends, and Economic Issues, 2009 Edition. Economic Research Report no. 73. Washington, DC: USDA, ERS.

10. Committee to Review the WIC Food Packages, Food and Nutrition Board (2005) WIC Food Packages: Time for a Change. Washington DC: The National Academies Press.

11. US Department of Agriculture, Food and Nutrition Service (2007) Special Supplemental Nutrition Program for Women, Infants and Children (WIC): Revisions in the WIC Food Packages; Interim Rule 7 CFR Part 246. 72. Washington DC: USDA; available at http://www.fns.usda.gov/wic/ lawsandregulations/WICRegulations-7CFR246.pdf

12. Hawkes C (2009) Financial incentives and disincentives to encourage healthy eating. http://www.which.co.uk/aboutwhich/who-we-are/which-policy/food/healthier-choices/ financial-incentives/ (accessed March 2014).

13. Gladson (2011) Nutrition Database. http://www.gladson com/SERVICES/NutritionDatabase/tabid/89/Default.aspx (accessed September 2013).

14. Andreyeva T, Luedicke J, Tripp AS et al. (2013) Effects of reduced juice allowances in food packages for the Women, Infants, and Children program. Pediatrics 131, 919-927.

15. US Department of Agriculture, Agricultural Research Service (2011) USDA National Nutrient Database for Standard Reference, Release 23. http://ndb.nal.usda.gov/ (accessed September 2013).

16. Reed J, Frazão E \& Itskowitz R (2004) How Much Do Americans Pay for Fruits and Vegetables? Agriculture Information Bulletin no. AIB-790. Washington, DC: USDA, ERS. 
17. US Department of Agriculture, Food and Nutrition Service (2008) Food Buying Guide for Child Nutrition Programs. http://www.fns.usda.gov/tn/resources/foodbuying guide.html (accessed September 2013).

18. Bowman SA, Friday JE \& Moshfegh A (2008) MyPyramid Equivalents Database 2.0 for USDA Survey Foods 20032004. Beltsville, MD: Beltsville Human Nutrition Research Center, ARS, USDA.

19. US Census Bureau (2010) 2006-2010 American Community Survey. Washington, DC: US Census Bureau.

20. Nichols A (2012) Regression for nonnegative skewed dependent variables. BOS10 Stata Conference 2 Stata Users Group 2010. http://repec.org/bost10/nichols_boston2010. pdf (accessed March 2014).

21. Hardin JW \& Hilbe J (2003) Generalized Estimating Equations. Boca Raton, FL: Chapman \& Hall/CRC.

22. Volpe R \& Okrent A (2012) Assessing the Healthfulness of Consumers' Grocery Purchases. Economic Information Bulletin no. EIB-102. Washington, DC: USDA, ERS.

23. US Department of Agriculture, Center for Nutrition Policy and Promotion (2013) Center for Nutrition Policy and
Promotion's low-cost food plan. http://www.cnpp.usda. gov/USDAFoodCost-Home.htm (accessed September 2013).

24. Bureau of Labor Statistics (2011) Consumer Expenditure Survey 2011. http://www.bls.gov/cex/csxstnd.htm\#2011 (accessed September 2013)

25. Committee on Nutrition, American Academy of Pediatrics (2001) The use and misuse of fruit juice in pediatrics. Pediatrics 107, 1210-1213.

26. American Academy of Pediatrics (2009) Caring for Your Baby and Young Child: Birth to Age 5 [SP Shelov, editor]. New York: Bantam Books.

27. Alberti P, Perlman S, Nonas C et al. (2010) Effects of switching from whole to low-fat/fat-free milk in public schools - New York City, 2004-2009. MMWR Morb Mortal Wkly Rep 59, 70-73.

28. Bartlett S, Klerman J, Wilde P et al. (2013) Healthy Incentives Pilot (HIP) Interim Report. Alexandria, VA: USDA, Food and Nutrition Service, Office of Research and Analysis.

29. Cunningham SA, Kramer MR \& Narayan KMV (2014) Incidence of childhood obesity in the United States. $N$ Engl J Med 370, 403-411. 